\title{
New Enhanced Method for Managing Database Project via Genetic Algorithm And Fuzzy Logic
}

\author{
Maryam KaivanluShahrestanaki \\ Department of Computer, Ferdows Branch, \\ Islamic Azad University \\ Ferdows, Iran
}

\author{
Dr.Hooman Kashanian \\ Department of Computer ,Ferdows Branch, \\ Islamic Azad University \\ Ferdows, Iran
}

\begin{abstract}
Practicable establishment between Project and its progress procedure is vital to yield the finest outcome but uncertainty is great challenge in such kind of formation. Set of related doings that has varying uncertainty characteristic named as Project. To manage such varying uncertain situation, it is vital to mold progress procedure flexibly as per terms and circumstances. This article has made deep endeavor for revision the phases to be commenced to design and discovers flexible methodology. This method is not combination or hybrid association of accessible methodology. It is providing independence to progress expert for select the progress method as per development needs of projects contributory module for project expansion. Main idea of this paper is to rectify the present difficulties and troubles in improvement process by representing 'Flexible approach' for development on the origin of 'Selection of software expansion procedure suggested system (SOSDMAS)-fuzzy expert system' for making competent development with possible and need base formation
\end{abstract}

Key words: Software design, Revolutionary algorithms, Software development, Genetic algorithm

\section{INTRODUCTION}

A Data acquisition (DAQ) system in common involves of The basic notion of the software expansion productivity depends mainly on two aspects, one is 'project' and another is 'development methodology' [24]. Thus, logically the success of project development process depends on the establishment of project and its development procedure. The revision reveals that, every project is unique but has set of contributory module with variable uncertainty level, on other hand it has effective option (development methodology) with best practice $[14,15]$. Therefore, it is challenging to define that which development procedure is appropriate for efficient development that will give best result, since each one has difficulties. Such kind of environments escalations the level of uncertainty and intricacy. In such condition it is very precarious and crucial to formulate possible formation of project and its development methodology as per its best practice for efficient development [19].Often it is mentioned as the "black art" or "brain tester" $[11,22]$. Now, development specialist do not have a magic wand threw that they formulate alignment between the project's interacting mechanisms and development procedure and project success.

Usually, 'success can be found by either by luck or insight of decreasing failure'. It is not only philosophy but our personal experience that in such inconstant variable circumstance, our method becomes flexible as per need of terms and situation to reduce failure. With this stimulus to rectify the failure part, this revision is carried out. The scientists have made workaholic ardent efforts by the way of distinctive permutations and combinations variables in the technological factors and analysis of relevant literature on "software development productivity and investigate its impact factors to reformulate and customize software and its strategy to gain expectation and design fallouts on the foundation of flexible approach.

In the paper planned in $\mathrm{V}$ sections:

Section I deals with overview of title of this paper.

Section II deals with limits in Software

Development Productivity, treats and chance in software development process

Section III deals with procedure and observation.

Section IV is lead with debate supported by implication, interpretation and recommendation.

The result and future work of study is depicted in section $\mathrm{V}$.

\section{SECTION II:}

\subsection{Restrains in Software Expansion}

Productivity: Many literate writers study explored that uncertainty is seed of threats in feasible formation of Project and its development procedure in software development process. Because of rigidity, plan driven method is incompetent to fetch such uncertain milieu [16]. Practice driven method provides competent result in such environment [8]. But still software expansion industries fetch the problem of failures or overruns $[9,18]$. Further though we have mix or hybrid method which treated one expansion methodology [13, 20 and 23]. In this review 'how one development procedure fits for all contributory modules development'? 


\subsection{Challenges for Software Expansion Procedure:}

To tackle the uncertainty is big challenge in front of expansion procedure. However it has practice driven method based particularly adopt uncertainty [15, 23] but project is set of contributory module that has variable aspect and level of uncertainty. So rather than variation of uncertainty development specialist must fetch the uncertainty by recognizing its sources and level. But projects contributory modules subsequent formation returns uncertainty module to module. In such condition there may be risks of an inaccurate handling of design method or hasty decision, which may be prove to be wrong later [2,3]. As consequence, expansion process become uncomfortable with variance situation and rise challenging state or overruns. Later it is one of the robust causes and limit for trip down the software project.

In such an uncertain condition, precious question is "How development specialist could formulate the project and its development procedure on the basis of feasible consideration?"

\subsection{Chance for Software Development Procedure:}

Based on review reports, there are some success stories. In such an uncertain condition 'How they become the successes or 'Do they have any mystic wand?' The answer is undeniably no because formulating the project and its expansion methodology on the basis of feasible consideration is very straight forward once one understands level of indecision and its sources [11, 22].This revision proposes the development practitioner comprehend project with its parallel activation formation because it distinguishes uncertainty its root sources module which is very helpful for allocation need base development approach as per to gain best productivity on the basis of flexibility in the sense of 'Just Utilization Gaining Approach And Deploy'.

Therefore our theory is "Flexible method for software expansion transfers opportunity for feasible formation of project and its development methodology"

\section{SECTION -III: PROCEDURE}

\subsection{Qualitative Solution for theory: In} this section the procedure of the revision has been discussed. The inductive method with qualitative solution is exploited to test the estimated hypothesis by experimental case study.

\subsection{Implementation of 'Flexible method' in the software expansion process.}

Flexible method: As the flexible methods principle goals to provide choice to decision maker to adopt the change as per terms and condition in accessible situation for produce better performance. It can be employed with such capability to deal with both predictable and unpredictable changes $[1,10,12$, and 17]. This method is adapting those ways for solution which is appropriate for accurate formulation of expansion process with feasible consideration.

It is appropriate for implementation in expansion process for development specialist. So, at the preliminary stage when user stories cognize at that time expansion practitioner can easily recognize uncertainty, its root sources with parallel formation contributory modules by rule base fuzzy expert system before modeling process for allocating suitable development methodology module wise for development. On the foundation of CMMI Level-2 \& 3,

"To make sure that accessible processes are maintained at the time of stress, organization use causal analysis to identify and resolve the issues affecting performance and promote the dissemination of finest practices by Organizational Process Performance, Quantitative Work Management”. 
Table 1: Module wise Uncertainty level and its allocated development methodology by SOSDMAS

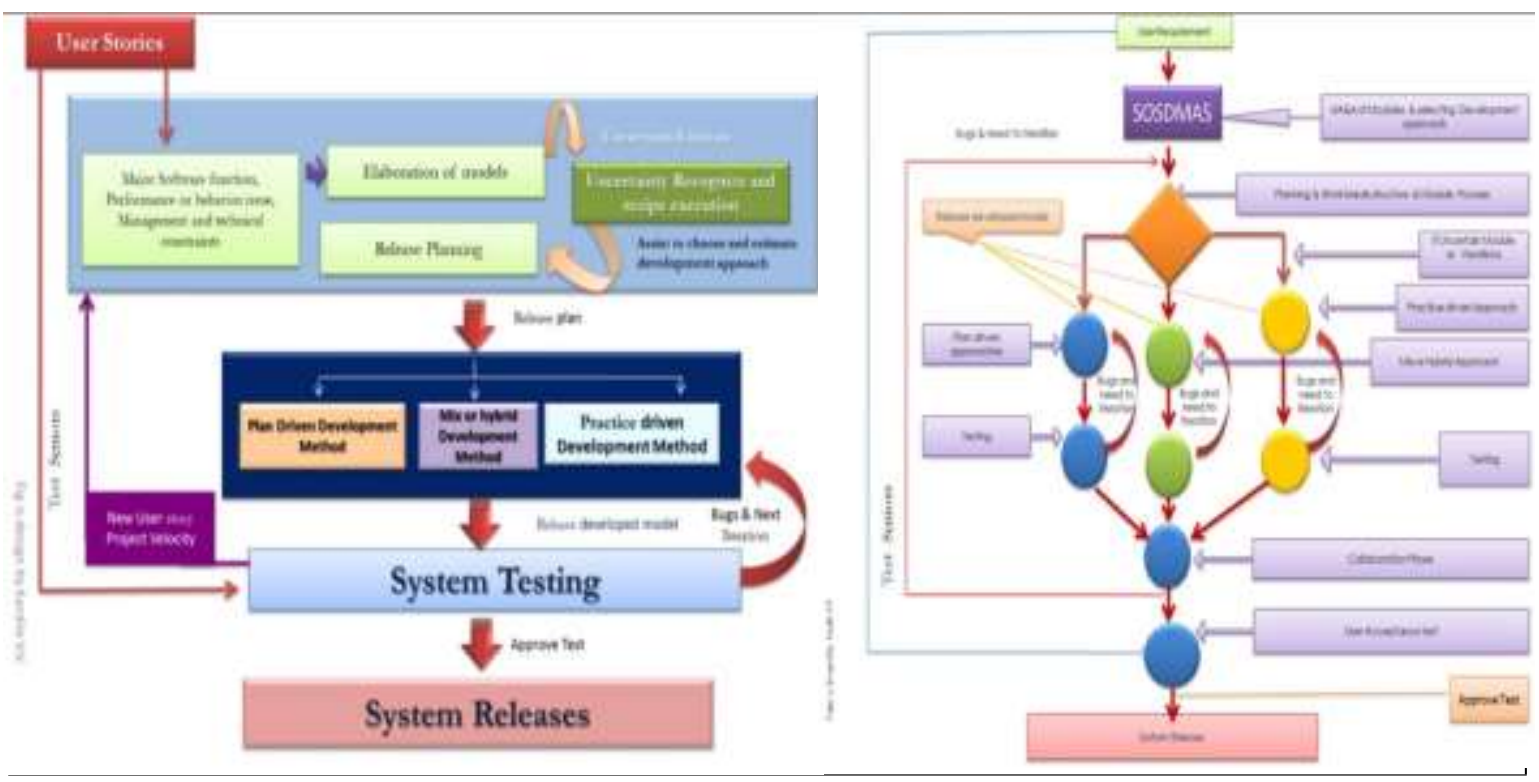

\subsection{Illustrative investigational case study using Flexible methodology}

For the determination of validation and to test the flexible model we exploit system testing and act testing on one experimental case study, let's consider the 'Log in' form as a project. User specifies necessities of ' $\log$ in' form module application that generates and preserves user's authentication of administration. It accumulates password from the user and authenticate it. It lets the new user to add information details. Give ability to recover the forgotten password by one or two phase of verification. Like subsequent screen as a project. This module has three sub actions as: Login ability, Sign up and forgot password.

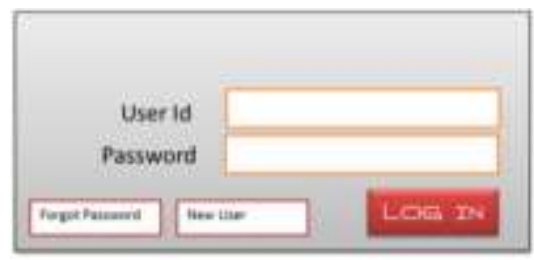

Figure 1: Illustrative Project need screen.

With own feature of project and necessity, development practitioner can surly celebrate this module along with practice driven method with outward appearance of agile development methodologies instead of plan driven approach. Because of its sub activity it enable recover the forgotten password by one or two step verification. 'One phase verification' celebrates some hint question or substitute mailing address. In two phase authentication it will require alternative service like mobile no, or it can regenerate randomly and received by the head of department. It is not approve. But when we focus on remaining two sub activities evidently it is notable in certain aspect.

But when we apply 'Selection of software expansion methodology advisory system' on the above case study the outcome interprets that above case study celebrates intricate aspect. So with this concern, researcher assigns three teams on same platform (core java) with plan, practice driven and flexible driven method following team as per following table for validate estimated theory.

These three expansion team included 4computer science topper student and 2 working software professional with 2 year experience in well apparent software development firm for development purpose of above case study.

Here we assign team on same platform (core java) with owed development approach as per following table.

Table 2. formation of expansion team for act testing of experimental case study development

\begin{tabular}{|c|c|c|}
\hline $\begin{array}{l}\text { Team } \\
\text { No }\end{array}$ & Team members & $\begin{array}{c}\text { Owed development } \\
\text { approach }\end{array}$ \\
\hline I & $\begin{array}{c}2 \text { software } \\
\text { professional }\end{array}$ & Practice driven (SCURM) \\
\hline
\end{tabular}


International Journal of Computer Applications Technology and Research

Volume 5- Issue 9, 584 - 589, 2016, ISSN:- 2319-8656

\begin{tabular}{|c|c|c|}
\hline II & $\begin{array}{c}\text { 1 M.Sc. } \\
\text { [Computer], 1 } \\
\text { U.G Level }\end{array}$ & Flexible method \\
\hline III & $\begin{array}{c}\text { 1 M.C.A. } \\
\text { [Computer], } \\
\text { U.G Level }\end{array}$ & $\begin{array}{c}\text { Plan driven method (Water } \\
\text { fall approach) }\end{array}$ \\
\hline
\end{tabular}

Result given by above team for develop experimental case study:

Table 3: Effort arrangement in Hours on Each Stage for above experimental case study

\begin{tabular}{|c|c|c|c|c|c|}
\hline $\begin{array}{l}\text { Strategy } \\
\text { Driven }\end{array}$ & $\begin{array}{l}\text { Time } \\
\text { (Hrs.) }\end{array}$ & $\begin{array}{l}\text { Practice } \\
\text { Driven }\end{array}$ & $\begin{array}{l}\text { Time } \\
\text { (Hrs.) }\end{array}$ & $\begin{array}{l}\text { Flexible } \\
\text { Method }\end{array}$ & $\begin{array}{l}\text { Time } \\
\text { (Hrs.) }\end{array}$ \\
\hline $\begin{array}{l}\text { Initial } \\
\text { Investigat }\end{array}$ & 5 & Inception & 5 & Inception & 5 \\
\hline Necessity & 7 & Elaborat & 2 & Elaborat & 3 \\
\hline System $E$ & 5 & Construd & 7 & Construct & 7 \\
\hline System $D$ & 10 & \multirow{3}{*}{ Testing } & \multirow{3}{*}{15} & \multirow{3}{*}{ Testing \& } & \multirow{3}{*}{10} \\
\hline $\begin{array}{l}\text { System } \\
\text { Testing }\end{array}$ & 8 & & & & \\
\hline $\begin{array}{l}\text { System } \\
\text { Execution }\end{array}$ & 2 & & & & \\
\hline Total & 37 & & 29 & & 25 \\
\hline
\end{tabular}

\section{Section - IV Observation and assessment}

\subsection{Statement}

Result discovers that flexible method driven development team is substantial because it takes less development time as compared to plan driven and practice driven development teams for above experimental case study development.

We are detected that,
$<$ Plan driven method following team activate systematically but it wonders behind alteration In contras

Practice driven approach following team effectively bid on project development but it is irritated by its expert perception.

$<$ The teams following Flexible method succeed to make it competent or need base development but it demands high coordination between team members.

\subsection{Assessment}

With this respect, as per our laboratory experiment the planned flexible model is efficient to reduce development time and minimizes risks. This will allow the software expansion to keep it low with suitable quality but it needs high monitoring and coordination in development process.

Additionally less expansion time reduces stress of development team and reduces development cost. It is directly interlinked with resource and schedule of expansion process. It also helps to make competent development or quality works that surly improve productivity.

Above thoughtfulness directly indicate "Flexible method for software development transfers chance for feasible formation of project and its development methodology"

4.3 Recommendation: It is true that we have a unlimited tool in the case of practice driven method that it adopt the uncertainty on the basis of agility. It delivers ability to expansion process to rapidly change its stage and direction in a particular way but the problem of failures or overruns remain same. Moreover we have newly arrived notion of mix or hybrid approach. Nevertheless it has mixture of both approach but it is treated as one type procedure. Here we never miscalculate the expansion process naturally involves inconstant changeable environment and one typed solution is not suitable to it. This revision reveals that problem is not sited in expansion methodology. It is located in formulation of 'Project', 'its expansion methodology' and 'success'. It should be conceivable by flexible formation or couple the project with finest practice of software development methodology on the basis of need to handle the uncertainty rather than adopting it. It should offer ability to choose the need base formation by taking into account the certainty or uncertainty aspect distinctly. But, in that problem, there is not much care reported or received so far.

4.4 Carrying out: Every software expansion organization have own procedure for project development management. It may be vary from the 
organization to organization but it needs to address similar problems contain for development process. Implementation of flexible method is convenient for expansion practitioner for development. It needs carrying out only uncertainty distinguishes and recipe process with projects parallel activation formation for clarification and validation of contributory modules level of uncertainty before modelling procedure. Through that expansion specialist be able assign project's needing base development approach as per its best practice for making efficient development. Left over process remains as it is.

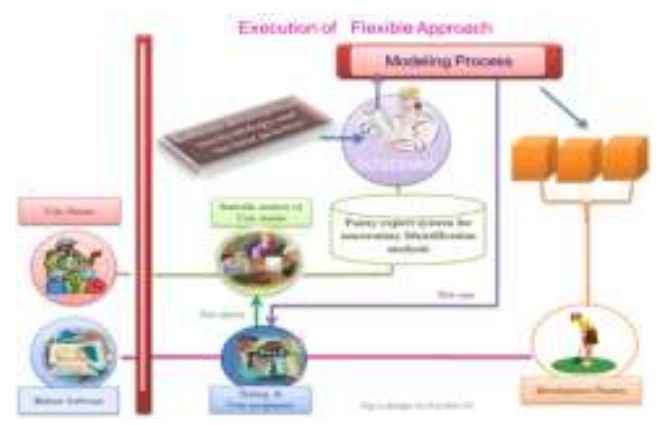

Figure 2: Performance of flexible method.

\section{Section $-V$}

\subsection{Result:}

In this section this revision released that possible formation of project and its expansion methodology as per its best practice formulation is not crucial or critical. Often it is denoted as the "black art" or "brain tester". It comes in presence with magic wand in the sense of flexible method. This revision hopefully conveys to the expansion specialist and trust that flexible approach transfers opportunity to enhance software development productivity. A flexible method may not be a complete solution for all software expansion difficulties; it could be opposed for those organizations that follow up one software expansion methodology to execute projects. But there is a demand to change as per terms and circumstances in available situation for enhancement.

\subsection{Opportunity of further work:}

As per literature analysis it is yet to publish announcement, which can explores the policy for decreasing the ratio of project challenges and cost overrun /time element. This revision found that, there is chance for lessening the ratio of project challenging and cost overrun /time element with flexible approach. In this section the revision learner agreed that this is very preliminary part of practice. There must be comprehensive authentications for proposed method.

\section{REFERENCES}

1. A. M. Gavkare, N. L.Nanaware, A. R.Waghmare, G.B. Taware, A. D.Surdi (2012)"Study of Flexibility, Agility and Reaction Time in Circus Artists" International Journal of Recent Trends in Science And Technology, E-ISSN 22398109, Volume 1, Issue 2, 2011 pp 49-55

2. Barry W. Boehm, TRW(2001)Improving Software productivity (csse.usc.edu/csse/TECHRPTS/1988/usccse87502/usccse87-501.pdf last access 31/02/12)

3. Boehm, B., \& Turner, R. (2005). Balancing Agility and Discipline: A guide for the Perplexed. Addison- Wesley.(book)

4. ChitraG.Desia ,Kardile, V $\mathrm{V}(2014)$ "uncertainty is not dilemma in software project development process" IEEE ISBN:978-1-7695-4437-3

5. ChitraG.Desia ,Kardile V V(2014)“uncertainty is not dilemma in software project development process"

IEEE ISBN:978-0-7695-4437-2

6. ChitraG.DesiaKardile V.V.(2014)“Jugaad"-the creativeness For Selection of software development methodology advisory system- Fuzzy expert system" presented at 2nd International Conference on

Computer and Communication Technologies (IC3T 2014) and published by Springer-Verlag

7. ChitraG.DesiaKardile V.V.(2014) Challenges in software development productivity -A literature review" Advances in computational research ISSN : 0975 -3973 DIO:10.97351975 3273 Volume

7,Issue 1

8. Chow, T., \& Cao, D. (2009). A Survey of Critical Success Factors in Agile Software Projects. The

Journal of Systems and Software, 81 (6), 961972.

9. Dr. Kevin Thompson, (2012)agile journal productivity report www.agilejournal.com , Articles > $\underline{\text { Columns > Articles) }}$

10. FerielDaoudiSelminNurcan(2009) "A benchmarking framework for methods to design flexible business processes"

11. Jens Christian Refsgaard a, *, Jeroen P. van der Sluijs b, Anker LajerHøjberg a, Peter A.

Vanrolleghemc,dJ.C. Refsgaard et al. (2009) Uncertainty in the environmental modelling process e A

framework and guidance Environmental Modelling \& Software 29 (2007) 1543-1556

12. Johan Bekar (1999) "Agility and flexibility what is difference" cranfield school of management ISBN 1 859050683

13. Juyun Cho reported "A hybrid software development method for large-scale projects: rational unified process with 
International Journal of Computer Applications Technology and Research

Volume 5- Issue 9, 584 - 589, 2016, ISSN:- 2319-8656

scrum" lume X, No. 2, 2008341 Issues in Information Systems

14. Lemétayer, J. (2012). Identifing the Critical Success Factors in Project Management Methodology Fit. PMI Global

Congress Proceedings. Melbourne, Australia

15. Little, T. (2008). Context-Adaptive Agility: Managing Complexity and Uncertainty. IEEE Software, $22(3), 28-36$

16. M. A. Awad (2008) "A Comparison between Agile and Traditional Software Development Methodologies"

17. Prestone G Smith, Jeff Oltmann (2015) "flexible project management: extended the agile technique beyond software project" PMI Global Congress Processing-Washington DC 2015.

18. Scott W. Ambler (2015) Defining Success, by. Dr. Dobb's Journal. source :2014 IT project success survey, 5 www.ambaysoft.com/surveys/ success2015.html

19. Shenhar, A. J. (2007). One Size Does Not Fit

All Projects: Exploring Classical Contingency Domains.

Management Science, 47 (3), 394-412
20. SiddharthSharadChandak.and Vishnu Rangarajan.is a Project Manager at Cognizant "Flexibility in Software Development Methodologies: Needs and Benefits"cognizant 20-20 insights , november 2011( last access 25 march 2013at google search)

21. Walker Royse(1999) "Software project management : Unified framework" forwarded by Barry Bohem

The Addison-Wesley object technology series

22. Walker, W.E., Harremoe s, P., Rotmans, J., Van der Sluijs, J.P., Van Asselt, M.B.A., Janssen, P., Krayer von Krauss, M.P., 2008. Defining uncertainty a conceptual basis for uncertainty management in modelbased decision support. Integrated Assessment 7 (1), $5 \mathrm{e} 16$

23. William Chaves de Souza Carvalho, Pedro Frosi Rosa, Michel dos Santos Soares reported (2018)“ A hybrid approach to integrate agile and traditional software development processes"

24. Wysocki, R. R. (2008). Efective Project Management: Traditional, Agile, Extreme (6th ed.). Indianapolis, IN: Wiley. 